\title{
Biting midges (Diptera: Ceratopogonidae) in Fushun amber reveal further biotic links between Asia and Europe during the Eocene
}

\author{
Frauke Stebner, Ryszard Szadziewski, and Bo Wang
}

\begin{abstract}
Investigation of fossils in lower Eocene Fushun amber from China keeps proving to be of major importance for understanding Eocene Euro-Asian insect diversity and distribution. Three new species of predatory biting midges in the fossil genera Mantohelea and Gedanohelea are described. Mantohelea sinica n. sp., Gedanohelea fushunensis n. sp. and Gedanohelea liaoningensis n. sp. from Eocene Fushun amber have their closest relatives in European Eocene Baltic amber. This not only expands generic distribution range from Europe to Asia but also strengthens the hypothesis that dispersal between both regions took place even though the Euro-Asian landmasses were separated by the Turgai Strait during the Eocene. In addition, the fossils supply evidence for a lower Eocene age of Baltic amber.
\end{abstract}

Frauke Stebner. Steinmann-Institut, Abteilung Paläontologie, Nussallee 8, 53115, Bonn, Germany. frauke.stebner@uni-bonn.de

Ryszard Szadziewski . University of Gdańsk, Department of Invertebrate Zoology and Parasitology, Wita Stwosza 59, 80-308 Gdańsk, Poland. ryszard.szadziewski@biol.ug.edu.pl

Bo Wang. State Key Laboratory of Palaeobiology and Stratigraphy, Nanjing Institute of Geology and Palaeontology, Chinese Academy of Sciences, Nanjing 210008, China. bowang@nigpas.ac.cn and Key Laboratory of Zoological Systematics and Evolution, Institute of Zoology, Chinese Academy of Science, Beijing 100101, China.

Keywords: new species; Fushun amber; Baltic amber; Eocene; Ceratopogonidae

Submission: 16 September 2015 Acceptance: 19 July 2016

\section{INTRODUCTION}

Fushun amber is collected in mining districts in the south of Fushun City, Liaoning Province, China. It is dated as lower Eocene (53 Ma) (e.g., Wang et al., 2014), at the beginning of the Early Eocene Climatic Optimum (EECO) (e.g., Zachos et al., 2008). Although Fushun amber has been known for over a century it has not been matter of scientific research until recently. A comprehensive study of inclusions from Fushun amber has revealed faunal links to Baltic amber, proven by a genus of scuttle flies (Eosciadocera Hong) (Wang et al., 2014).

http://zoobank/B38CB37D-3BF7-4D37-BA0C-102BC9DFE430

Stebner, Frauke, Szadziewski, Ryszard, and Wang, Bo. 2016. Biting midges (Diptera: Ceratopogonidae) in Fushun amber reveal further biotic links between Asia and Europe during the Eocene. Palaeontologia Electronica 19.3.31A: 1-9

palaeo-electronica.org/content/2016/1564-biting-midges-in-fushun-amber 
Biting midges (Ceratopogonidae) are a large, relatively well-studied family of Diptera. The recent world fauna comprises 6267 extant species grouped in 111 genera and four subfamilies (Borkent, 2016). The family has a rich fossil record from the Lower Cretaceous to the Miocene with 283 species (Borkent, 2016). With 109 named species in 26 (seven fossil, 19 extant) genera recorded (Szadziewski, 1988; Sontag and Szadziewski, 2011), the Eocene Baltic amber fauna is the best studied one.

Until now, only two fossil biting midges have been formally described from Fushun amber: one in the extant genus Forcipomyia Meigen, 1818 (Hong, 1981, Szadziewski, in press) and one in the fossil genus Eopalpomyitis Hong et al., 2000 (Hong 1981, 2002). It is worth mentioning that Sinopogonites eocenicus Hong, 2002 is an invalid name because it was proposed for a biting midge after 1999 without a specified type depository (Evenhuis, 2014).

The purpose of this work is to describe three new species of biting midges from Fushun amber, to provide keys to fossil species of the genera Mantohelea and Gedanohelea and to discuss biogeographic implications as well as the relevance of Fushun amber inclusions for age determination of Baltic amber.

\section{MATERIAL AND METHODS}

Amber specimens are deposited at the Nanjing Institute of Geology and Palaeontology (NIGP), Chinese Academy of Sciences, Nanjing, China. Samples have been ground and polished to pieces of the minimum size possible using a Buehler Phoenix Beta grinding machine.

For taxonomic identification and descriptions, a Leica MZ 12.5 Stereomicroscope and a MZ 16 Stereomicroscope were used. Drawings were prepared with the aid of a drawing tube and performed with Adobe Illustrator CS5.1. Measurements are given in millimeters. Photographs of the amber inclusions were made with a Leica MZ 16 Stereomicroscope with a JVC ky-F70B Digital Camera. Compound photographs merging different focal levels to a single image were created by using Discus software equipped with a stacking function.

The special morphological terms and abbreviations used in the paper follow Szadziewski (1988, 1996). The following abbreviations are used: $A R=$ antennal ratio, obtained by dividing the combined length of the elongate distal flagellomeres by the combined length of the proximal flagellomeres; TR $=$ tarsal ratio, obtained by dividing the length of the basitarsus by the length of the second tarsomere; $\mathrm{CR}=$ costal ratio, obtained by dividing the length of the costa by the wing length. The ratio of divergence between $M_{1}$ and $M_{2}$ has been calculated for species of Gedanohelea by dividing the distance between the end of $M_{1}$ and $M_{2}$ by the total wing length.

For generic identification, the determination key of Szadziewski (1988) was used. The tribal placement of both genera expanded in the current paper follows that of Borkent (2016).

\section{RESULTS}

\section{Systematic Palaeontology}

Family CERATOPOGONIDAE Newman, 1834 Subfamily CERATOPOGONINAE Newman, 1834 Tribe CERATOPOGONINI Newman, 1834 Genus MANTOHELEA Szadziewski, 1988

Type Species. Ceratopogon lacus Meunier, 1904, by original designation.

Diagnosis. Medium-sized predatory biting midges characteristic in having a single first radial cell, median veins petiolate, and fore femur swollen and armed with strong ventral spines.

Distribution and Age. Fossil genus including Mantohelea laca (Meunier, 1904) and Mantohelea gedanica Szadziewski, 1988 described from Eocene Baltic amber. Reported from Eocene Asia for the first time herein.

Mantohelea sinica n. sp.

Figures 1.1, 1.2, 2.1-8

\section{zoobank/B37DEC3E-A6F9-4EC6-A34F-FA65B2AAD33E}

Material. Holotype female NIGP156996. Deposited at the Nanjing Institute of Geology and Palaeontology, Chinese Academy of Sciences.

Etymology. The specific epithet is derived from Latin name of China - Sina.

Diagnosis. The species is characteristic in having weakly swollen femur of foreleg armed with long slender ventral spines, fore tibia without apical prolongation, hind femur without strong setae and palpus with short palpomere 4. Males unknown.

Description. Female. Dark brown in colour. Total body length (including head) $1.3 \mathrm{~mm}$.

Head. Eye separation not visible. Flagellum length $0.50 \mathrm{~mm}$. AR 1.26. Antenna with 13 flagellomeres, flagellomeres 2-8 gradually increasing in length, distal 5 flagellomeres distinctly elongate (Figure 2.1). Proboscis long. Palpus slender; palpal segment 4 is 0.75 the length of palpal segment 3 (Figure 2.3); sensory pit absent. 

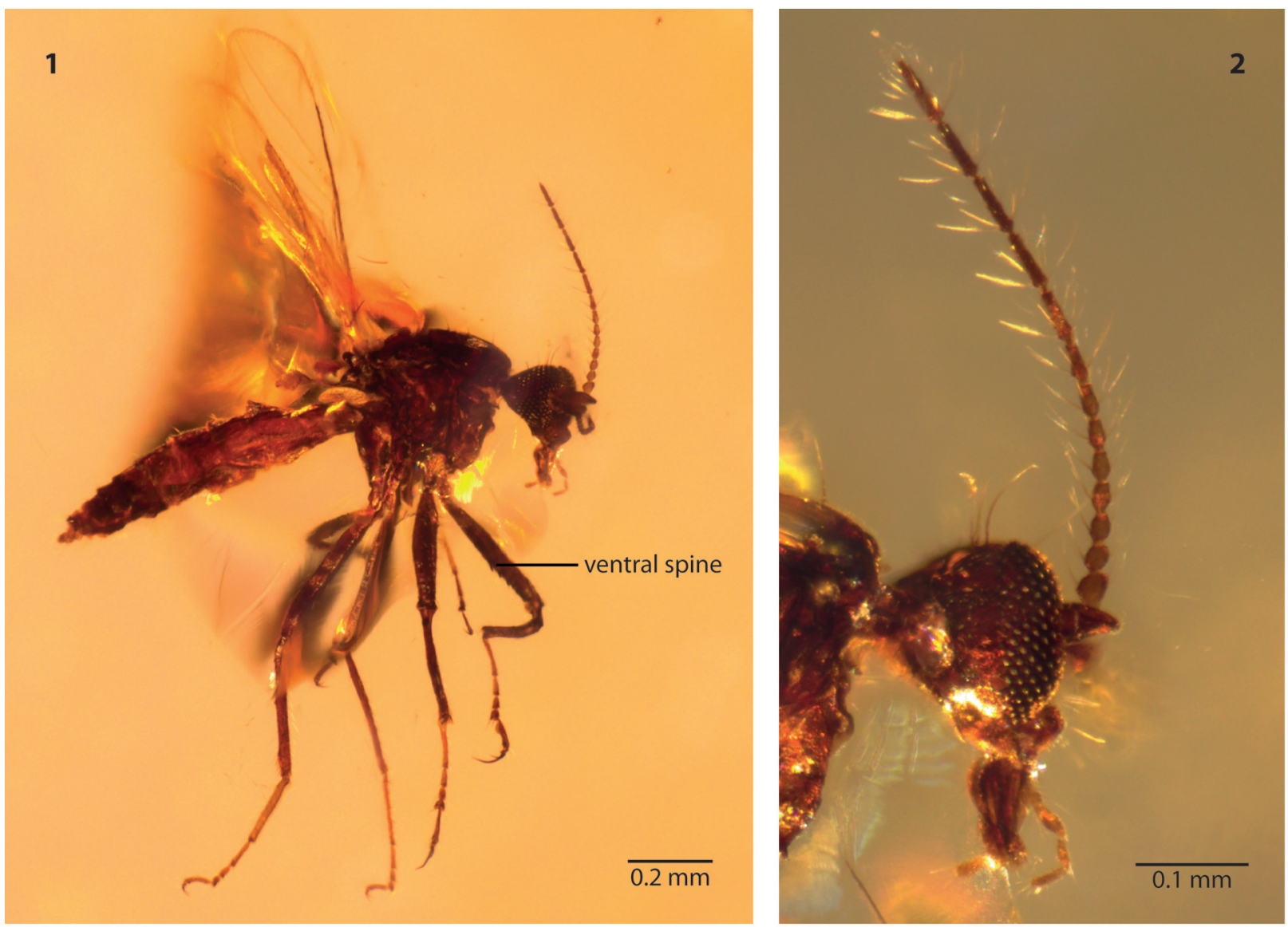

FIGURE 1. Photograph of Mantohelea sinica n. sp. from lower Eocene Fushun amber. 1. Mantohelea sinica n. sp., Holotype female NIGP156996. 2. Mantohelea sinica n. sp., head.

Thorax. Antepronotum well developed, collar like. Forelegs with femur (Figure 2.5) slightly swollen (shape similar for both legs, no evidence for distortion - so this character state is regarded to be not an artefact or taphonomic result), armed with seven long and slender ventral spines; lateral spines not visible. Fore tibia (Figure 2.4) somewhat arcuate with singular apical spur; apical prolongation absent. Tarsomere 5 of foreleg with basal enlargement (Figure 2.6). Mid leg slender, basitarsus with four spine-like setae (Figure 2.7). Hind femur and tibia slightly enlarged, tibial comb composed of at least five strong spines, hind basitarsus with complete row of palisade setae (Figure 2.8). Tarsomeres 4 short, cordiform. Claws slightly unequal, simple; claws of foreleg distinctly longer that those of mid and hind legs. TR(I) 2.18, TR(II) 3.21, TR(III) 2.38. Wing length $0.8 \mathrm{~mm}, \mathrm{CR} 0.63$. Radial cell single, media with short stem (Figure 2.2). Membrane without macrotrichia, microtrichia not visible.
Abdomen. Cerci short, oval. Seminal capsules not visible.

Remarks. The species resembles Mantohelea gedanica in the proportions of palpal segments 4 and 3 and in the absence of spine-like setae on the hind femur. Both species differ however in the fore femur, which is less swollen in Mantohelea sinica (Table 1).

Genus GEDANOHELEA Szadziewski, 1988

Type Species. Gedanohelea loewi Szadziewski, 1988 , by original designation.

Diagnosis. Very small predatory biting midges characteristic in having a broad wing with large anal lobe, single small radial cell, media petiolate, with $M_{1}$ bowed upward distally and reaching wing margin distinctly anterad of wing tip, tarsi short, and female claws long and single.

Distribution and Age. Fossil genus including Gedanohelea wirthi, Gedanohelea succinea, and Gedanohelea loewi described from Eocene Baltic 

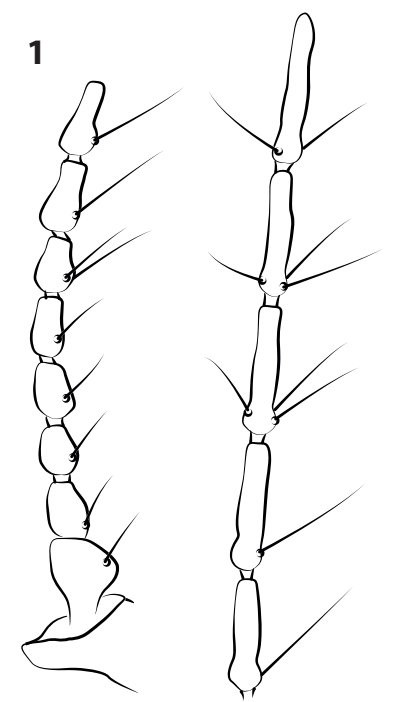

2
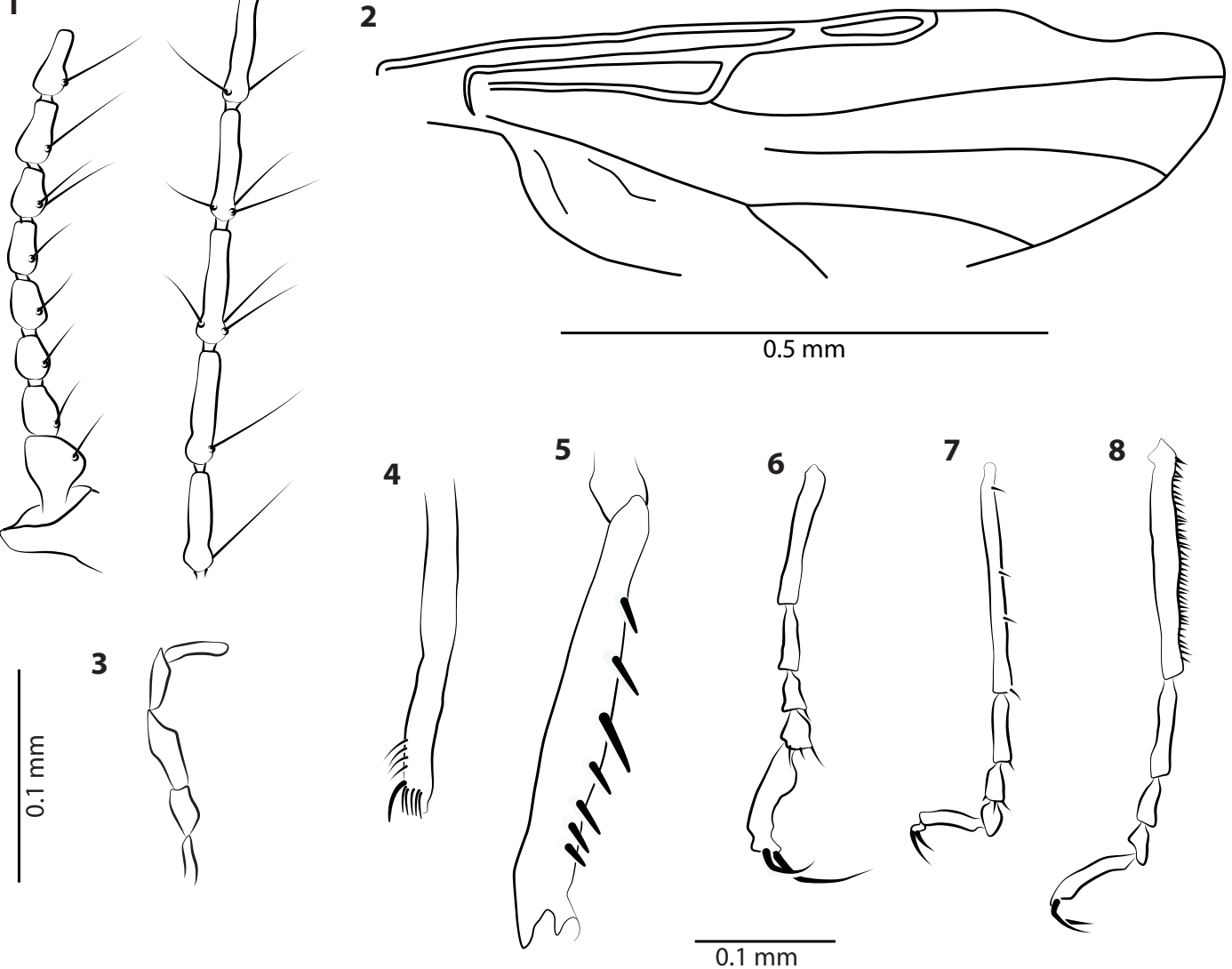

FIGURE 2. Mantohelea sinica n. sp., Holotype female NIGP156996. 1. Antenna. 2. Wing. 3. Palpus. 4. Fore tibia. 5. Fore femur. 6. Tarsus of foreleg. 7. Tarsus of mid leg. 8. Tarsus of hind leg.

amber (Szadziewski, 1988). Reported from Eocene Asia for the first time herein.

Gedanohelea fushunensis n. sp.

Figures 3.2, 3.4, 4.1-6

zoobank/E7DAEDF9-A71D-4AA7-B4CF-9B0126CA1971

Material. Holotype female NIGP156997. Deposited at the Nanjing Institute of Geology and Palaeontology, Chinese Academy of Sciences.

Etymology. The specific epithet refers to the city of Fushun near where the amber is collected.

Diagnosis. The species is characteristic in having cylindrical palpal segments 3 and 4 and wing veins $\mathrm{M}_{1}$ and $\mathrm{M}_{2}$ strongly divergent. Males unknown.

Description. Female. Dark brown in colour, partially distorted, wing venation only poorly visible. Total body length (including head): $1.2 \mathrm{~mm}$.

Head. Flagellum length $0.37 \mathrm{~mm}$. AR 0.95 . Antenna with 13 cylindrical flagellomeres, distal 5 flagellomeres distinctly elongate, last flagellomere longest (Figure 4.1). Flagellomere 12 appears enlarged but this most probably an artefact. Palpus (Figure 4.3) short, with five segments, only terminal three palpal segments clearly visible, about 0.072 $\mathrm{mm}$ in length, palpal segments 3 and 4 cylindrical, palpal segment 3 with distinct sensory pit.

Thorax. Legs slender, unarmed. Hind basitarsus with row of palisade setae. Tarsomeres 2-4 short, tarsomere 4 cordiform, tarsomere 5 longer than preceding ones but shorter than combined length of tarsomeres 2-4. Tibial comb composed of six spines. Claws (Figure 4.4-6) single on all legs, claw of foreleg as long as tarsomere 5 , claws of midand hind leg shorter. TR(I) 2.86, TR(II) 3.50, TR(III) 3.57. Wing length: $0.65 \mathrm{~mm}, \mathrm{CR} 0.47$. Ratio of divergence between $M_{1}$ and $M_{2}: 0.29$. Veins poorly visible, $M_{1}$ and $M_{2}$ (Figure 4.2) strongly divergent, $M_{1}$ meeting wing margin at right angle. Membrane without macrotrichia, microtrichia present.

Gedanohelea liaoningensis $\mathrm{n} . \mathrm{sp}$.

Figures 3.1, 3.3, 5.1-6

zoobank/F996CF73-439C-4A48-8C69-5C451B709E68 
TABLE 1. Key to the species of Mantohelea.

1. Fore femur slightly swollen (Figure 2.5). Apex of fore tibia without prolongation

-. Fore femur greatly swollen. Apex of fore tibia with distinct prolongation

2. Palpal segment 4 slightly shorter than palpal segment 3

-. $\quad$ Palpal segment 4 almost 2 times shorter than palpal segment 3
M. sinica n. sp

2

M. laca (Meunier, 1904)

M. gedanica Szadziewski, 1988
Material. Holotype female NIGP156998. Deposited at the Nanjing Institute of Geology and Palaeontology, Chinese Academy of Sciences.

Etymology. The specific epithet refers to the province of Liaoning, from where the amber is collected.

Diagnosis. The species can be distinguished by having wing veins $M_{1}$ and $M_{2}$ slightly divergent, vein $M_{1}$ reaching wing margin at acute angle, and palpal segments 3-4 cylindrical. Males unknown.

Description. Female. Dark brown to black in colour, both antennae broken. Total body length (including head) $0.91 \mathrm{~mm}$.

Head. Flagellum length $0.39 \mathrm{~mm}$, AR 0.92 . Antenna with 13 cylindrical flagellomeres, both antennae broken beyond flagellomere 8 but distal 5 flagellomeres of left antenna preserved and dis-
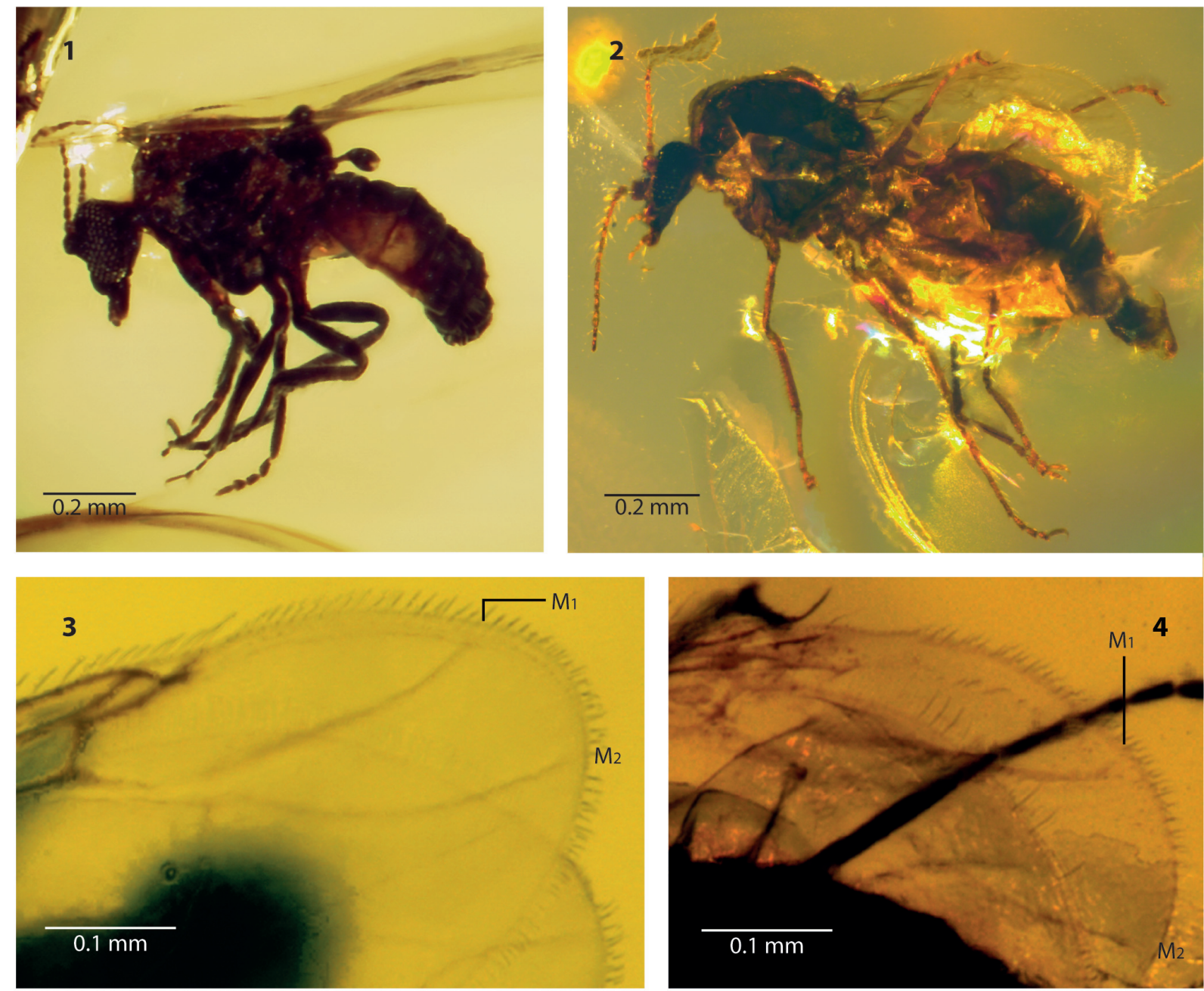

FIGURE 3. Photograph of Gedanohelea fushunensis n. sp. and Gedanohelea liaoningensis n. sp. from lower Eocene Fushun amber 1. Gedanohelea liaoningensis n. sp., Holotype female NIGP156998. 2. Gedanohelea fushunensis n. sp., Holotype female NIGP156997. 3. Detail of wing of Gedanohelea liaoningensis n. sp. with tips of veins $M_{1}$ and $M_{2}$ marked. 4. Detail of wing of Gedanohelea fushunensis $n$. sp. with tips of veins $M_{1}$ and $M_{2}$ marked. 

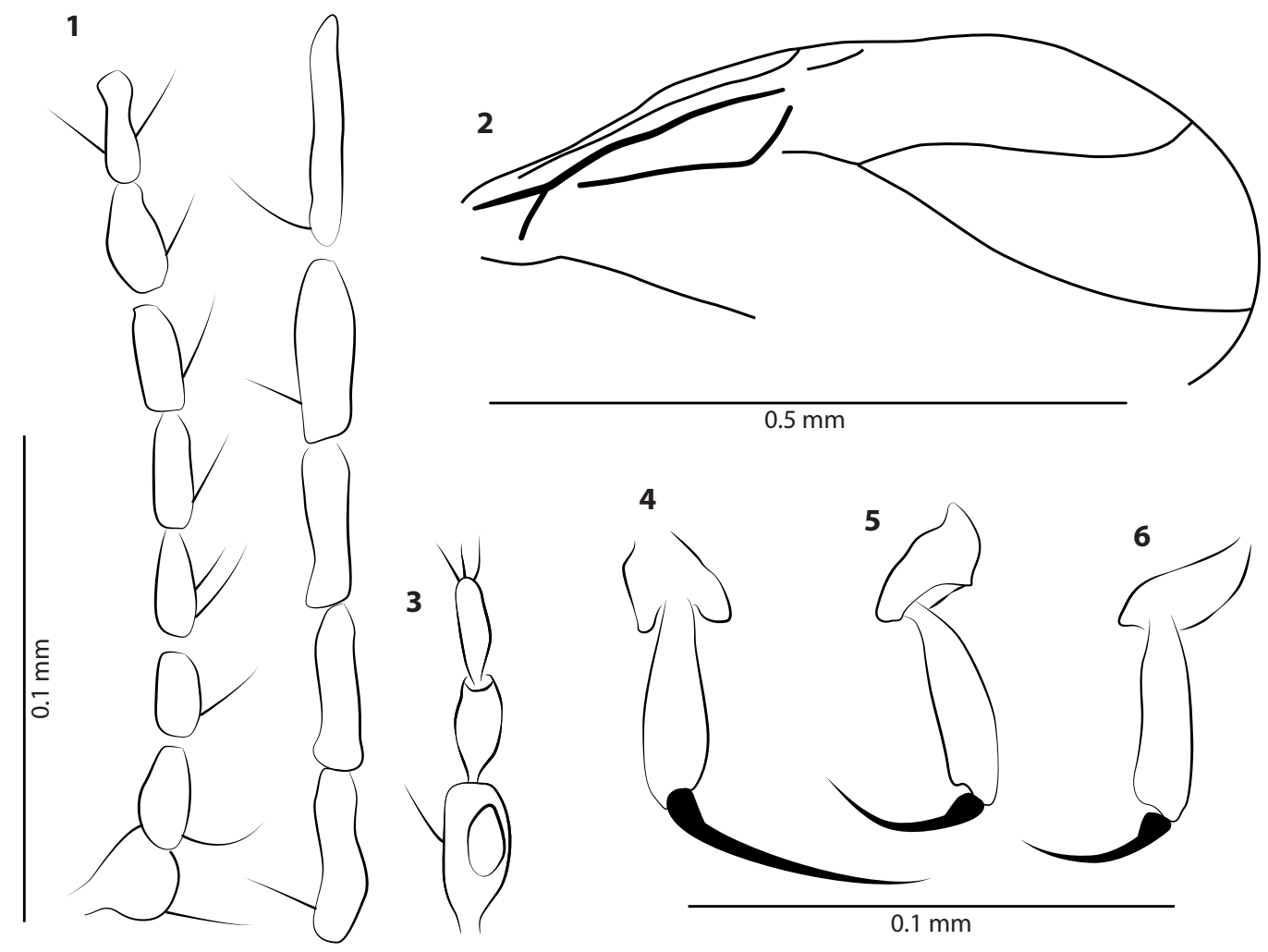

FIGURE 4. Gedanohelea fushunensis n. sp., Holotype female NIGP156997. 1. Flagellum. 2. Wing. 3. Palpal segments 3-5. 4. Tarsomeres 4, 5 and claw of foreleg. 5. Tarsomeres 4, 5 and claw of mid leg. 6. Tarsomeres 4, 5 and claw of hind leg.

tinctly elongate, last flagellomere longest (Figure 5.1). Palpus (Figure 5.3) short, most probably with five segments but only terminal three segments clearly visible and about $0.054 \mathrm{~mm}$ in length, palpal segment three cylindrical, apparently not distinctly broader than following segments.

Thorax. Hind basitarsus with row of palisade setae. Tarsomeres 2-4 short, tarsomere 4 cordiform, tarsomere 5 longer than preceding one but shorter than combined length of tarsomeres 2-4. Tibial comb composed of at least six spines. Claws single on all legs; claw of foreleg (Figure 5.4) as long as tarsomere 5, claw of mid- and hind legs shorter (Figure 5.5-6). TR(I) 2.67, TR(II) ?, TR(III) 3.57. Wing length $0.65 \mathrm{~mm}, \mathrm{CR} 0.51$. Ratio of divergence between $M_{1}$ and $M_{2}: 0.25$. Veins $M_{1}$ and $M_{2}$ slightly divergent, $M_{1}$ reaching wing margin at acute angle (Figure 5.2).

Remarks. Gedanohelea liaoningensis n. sp. and Gedanohelea fushunensis n. sp. closely resemble each other. The only character that separates both species is the shape of the $M$ veins, which are less divergent in G. liaoningensis. In G. fushunensis $\mathrm{M}_{1}$ meets the wing margin at right angle, while $M_{1}$ reaches the wing margin at acute angle in $\mathrm{G}$. liaoningensis.

Having tarsomere 5 of foreleg distinctly shorter than combined length of tarsomeres 2-4, and the claw of foreleg almost as long as tarsomere 5 Gedanohelea liaoningensis and G. fushunensis resemble the Baltic amber species $G$. loewi. The species differ from each other in the shape of palpal segment 3 , which is almost spherical and bearing a small round sensory pit in Gedanohelea loewi but cylindrical in the two Fushun amber species and with a broad oval sensory pit in G. fushunensis. Furthermore, in G. fushunensis vein $M_{1}$ meets the wing margin exactly at $90^{\circ}$ instead of an acute angle as in $\mathrm{G}$. loewi.

$G$. fushunensis can be separated from Gedanohelea wirthi by the length of the claws, which are short on all legs in G. wirthi whereas the claw of the foreleg is long in $G$. fushunensis, and by the lower ratio of divergence of wing veins $M_{1}$ and $\mathrm{M}_{2}$, which is 0.29 in $G$. fushunensis and 0.34 in $G$. wirthi (Table 2). 

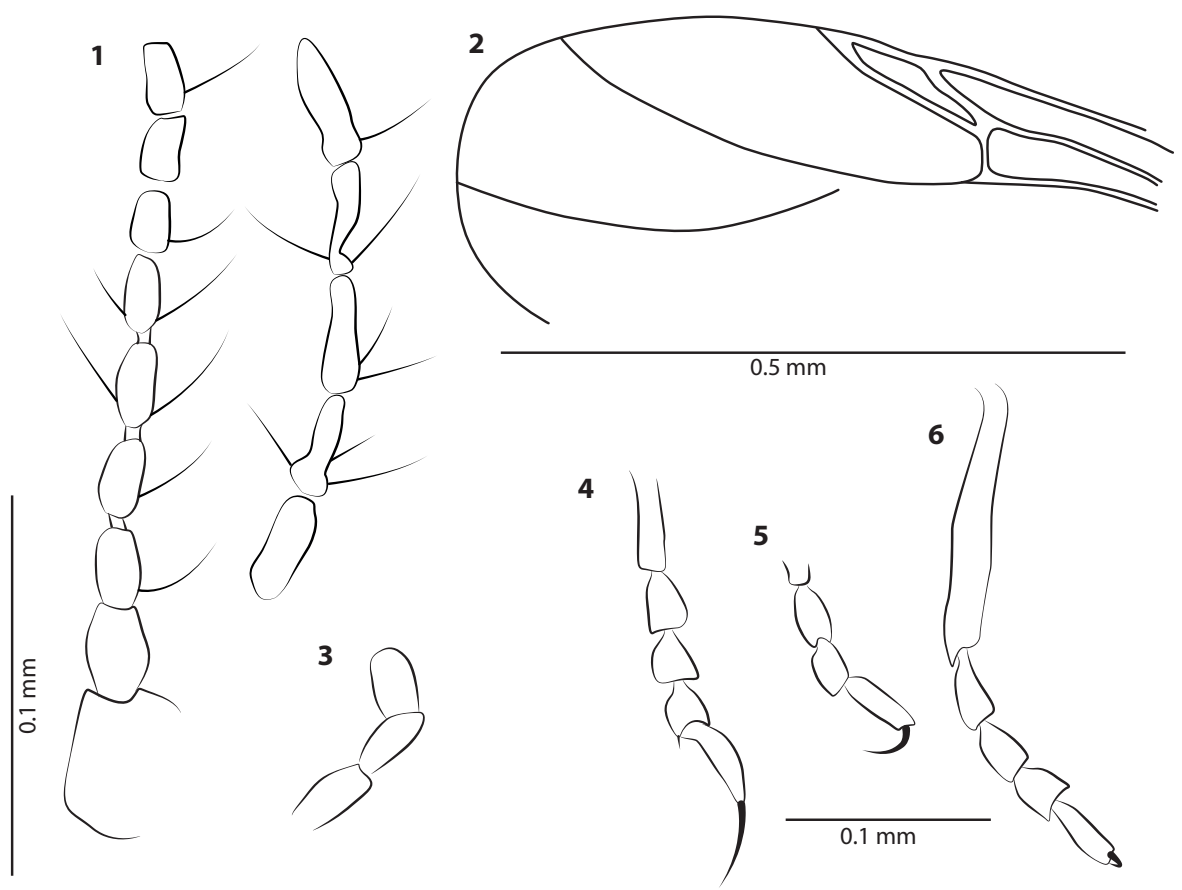

FIGURE 5. Gedanohelea liaoningensis n. sp., Holotype female NIGP156998. 1. Flagellum. 2. Wing. 3. Palpal segments 3-5. 4. Tarsus of foreleg. 5. Tarsus of mid leg. 6 . Tarsus of hind leg.

\section{DISCUSSION}

Specimens studied in the present work are partially distorted and dark brown to black in colour, which is characteristic for Fushun amber inclusions and most probably caused by heating of the amber during diagenesis (Wang et al., 2014). The two fossil genera Mantohelea and Gedanohelea recorded here from Fushun amber have previously been known only from two and three species, respectively, from Baltic amber (Szadziewski, 1988; Szadziewski et al., 2007) and confirm recently reported faunal affinities between both deposits (Wang et al., 2014). Our findings imply that these genera had a broader distribution in the Eocene than so far known, covering Europe and north-eastern Asia. The Euro-Asian landmass (Europe and Asia) was divided from the Cretaceous to the early Paleogene by the epicontinental Turgai Strait (Figure 6) resulting in low intercontinental dispersal rates of non-marine taxa, including insects, between the eastern and western lands, which increased only after the closing of the Turgai Strait at about $30 \mathrm{Ma}$ (Rögl, 1999; Sanmartin et al., 2001). Even so, distribution patterns of Mantohelea and Gedanohelea imply that faunal exchange between the eastern and western margins of the Eurasian landmass

TABLE 2. Key to the species of Gedanohelea.

1. Veins $M_{1}$ and $M_{2}$ strongly divergent (Figure 4.2)

2

Veins $M_{1}$ and $M_{2}$ slightly divergent (Figure 5.2)

2. Vein $M_{1}$ reaching wing margin at acute angle, palpal segment 3 spherical, claws of all legs short

-. $\quad$ Vein $\mathrm{M}_{1}$ reaching wing margin exactly at right angle (Figure 4.2), palpal segment 3 cylindrical, claw of foreleg long

3. Tarsomere 5 of foreleg as long as combined length of tarsomeres 2-4

-. Tarsomere 5 of foreleg distinctly shorter than combined length of tarsomeres 2-4

4. Palpal segment 3 spherical

-. Palpal segment 3 cylindrical
3

G. wirthi Szadziewski, 1988

G. fushunensis n. sp

G. succinea Szadziewski, 1988

4

G. loewi Szadziewski, 1988

G. liaoningensis $\mathrm{n}$. sp. 


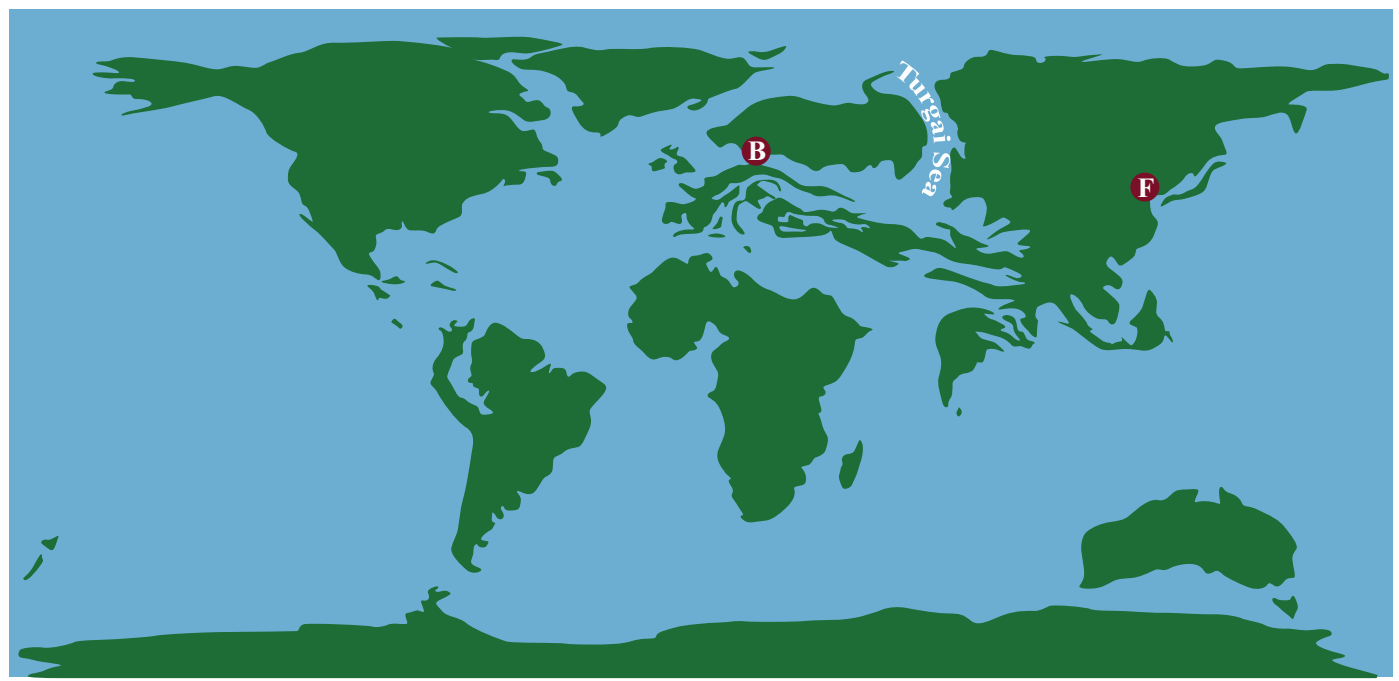

FIGURE 6. Palaeogeographic locations of early Eocene insect faunas in (approximately 50 Ma) Baltic amber (B) from Europe and Fushun amber (F) from China (modified after Blakey, 2015).

occurred during the Eocene, probably either by trans-oceanic dispersal or via temporary land bridge connections caused by sea level falls (lakovleva et al., 2001). The latter scenario is supported by land vertebrate dispersal (Godinot and Lapparent de Broin, 2003; Smith et al., 2006). Fushun amber contains the first insect indicators that the Turgai region allowed dispersal, and further studies are likely to keep revealing even more evidence.

Detailed studies of Fushun amber inclusions also are of relevance for age determination of Baltic amber, which still is matter of debate. Difficulties in age determination are due to repeatedly redeposition of the amber, the broad range of the ancient forest and its existence for probably several million years. Palynological studies date the Prussian Formation of Baltic amber as upper Eocene in age (ca. 39-33.9 Ma) (Aleksandrova and Zaporozhets, 2008) whereas absolute radiometric dating analyses of glauconites suggest a lower to middle Eocene age (48.5-43 Ma) for this formation (Ritzkowski, 1997).

Further evidence for a middle Eocene age of Baltic amber comes from correlations with limnic sediments within Eckfeld maar, which are dated $44.3 \pm 0.4 \mathrm{Ma}$ (Mertz et al., 2000) and contain insect groups that are otherwise known only from the geographically near Baltic amber (Wappler, 2003; Wappler and Engel, 2003; Wappler and Andersen, 2004).

Further contribution to the controversial discussion about the age of the amber deposits from the Baltic region is now provided by Fushun Ceratopogonidae whose close relationships to Baltic amber species imply a lower Eocene age for the Baltic amber. Considering that the amber forests in the Baltic region persisted for several million years, up to the end of the Eocene (e.g., Weitschat and Wichard, 2010), this finding does not contradict the faunal similarities between Baltic amber and the Eckfeld maar. Nevertheless, further studies on insect taxa from Fushun amber as well as other contemporaneous European and Asian ambers, such as Oise amber from France and Cambay amber from India, are needed to confirm our conclusions.

\section{ACKNOWLEDGEMENTS}

F.S. was supported by a funding to J. Rust (Steinmann Institut, Universität Bonn) No. RU665/ 10-1 from the German Research Foundation (DFG). B.W. was supported by the National Natural Science Foundation of China (41572010), and a Research Fellowship from the Alexander von Humboldt Foundation. F.S. would like to thank J. Rust (Steinmann Institut, Universität Bonn) for his continuous support and T. Wappler (Steinmann Institut, Universität Bonn) for his untiring help.

\section{REFERENCES}

Aleksandrova, G.N. and Zaporozhets, N.I. 2008. Palynological characteristics of Upper Cretaceous and Paleogene deposits on the west of the Sambian Peninsula (Kaliningrad Region), Part 2. Stratigraphy and Geological Correlation, 16:528-539. 
Blakey, R.C. 2015. Global Paleogeography, Mollewide Globes, Eocene (50 Ma). http://cpgeosystems.com/ 050Marect.jpg.

Borkent, A. 2016. World species of biting midges (Diptera: Ceratopogonidae). wwx.inhs.illinois.edu/files/ 4514/6410/0252/CeratopogonidaeCatalog.pdf (accessed 15 August 2016).

Evenhuis, N.L. 2014. Catalog of the Fossil Flies of the World (Version 2.0). http://hbs.bishopmuseum.org/ fossilcat/ (accessed 18 March 2014).

Godinot, M. and de Lapparent de Broin, F. 2003. Arguments for a mammalian and reptilian dispersal from Asia to Europe during the Paleocene-Eocene boundary interval. Deinsea, 10:255-275.

Hong, Y.-C. 1981. Eocene Fossil Diptera Insecta in Amber of Fushun Coalfield. Geological Publishing House, Beijing.

Hong, Y.-C. 2002. Amber Insects of China. Beijing Science and Technology Publishing House, Beijing. (In Chinese with English summary)

Hong, Y.-C., Guo, X.-R., and Ren, D. 2000. A new genus -Eopalpomyitis gen. nov. from Eocene Fushun amber and discussion of its taxonomic position. Acta Parasitologica et Medica Entomologica Sinica, 7:225-234.

lakovleva, A.I., Brinkhuis, H., and Cavagnetto, C. 2001. Late Palaeocene-early Eocene dinoflagellate cysts from the Turgay Strait, Kazakhstan; correlations across ancient seaways. Palaeogeography, Palaeoclimatology, Palaeoecology, 172:243-268.

Meigen, J.W. 1818. Systematische Beschreibung der bekannten europäischen zweiflügeligen Insekten. Vol. 1. Forstmann, Aachen.

Mertz, D.F., Swisher, C.C., Franzen, J.L., Neuffer, F.O., and Lutz, H. 2000. Numerical dating of the Eckfeld maar fossil site, Eifel, Germany: a calibration mark for the Eocene time scale. Naturwissenschaften, 87:270-274.

Meunier, F. 1904. Monographie des Cecidomyidae, des Sciaridae, des Mycetophilidae et des Chironomidae de l'ambre de la Baltique. Annales de la Société Scientifique de Bruxelles, 28:12-264.

Newman, E., 1834. Attempted division of British insects into natural orders. Entomological Magazine, 2:379431.

Ritzkowski, S. 1997. K-Ar-Altersbestimmungen der bernsteinführenden Sedimente des Samlandes (Paläogen, bezirk Kaliningrad). Metalla (Sonderheft), 66:1923.

Rögl, F. 1999. Mediterranean and Paratethys. Facts and hypotheses of an Oligocene to Miocene paleogeography (short overview). Geologica Carpathica, 50(4):339-349.

Sanmartin, I., Enghoff, H., and Ronquist, F. 2001. Patterns of animal dispersal, vicariance and diversification in the Holarctic. Biological Journal of the Linnean Society, 73:345-390.
Smith, T., Rose, K.D., and Gingerich, P.D. 2006. Rapid Asia-Europe-North America geographic dispersal of earliest Eocene primate Teilhardina during the Paleocene-Eocene Thermal Maximum. Proceedings of the National Academy of Science, 103(30):11223-11227.

Sontag E. and Szadziewski R. 2011. Biting midges (Diptera: Ceratopogonidae) in Eocene Baltic amber from the Rovno region (Ukraine). Polish Journal of Entomology, 80:779-800.

Szadziewski, R. 1988. Biting midges (Diptera, Ceratopogonoidae) from Baltic amber. Polski Pismo Entomologiczne, 57:3-283.

Szadziewski, R. 1996. Biting midges from Lower Cretaceous amber of Lebanon and Upper Cretaceous Siberian amber of Taimyr (Diptera, Ceratopogonidae). Studia Dipterologica 3:23-86.

Szadziewski, R. 2008. Age and recent distribution of extant genera of Ceratopogonidae (Diptera) present in fossil record. Alavesia, 2:87-99.

Szadziewski, R. (in press). Ceratopogonidae. In Krzeminski,W., Blagoderov, V., Azar, D., Lukashevich, E., Szadziewski, R., Wedmann, S., Nel, A., Collomb, F.M., Waller, A., Nicholson, and D.B. (eds.). True Flies (Insecta: Diptera) from the Eocene-Oligocene of the Isle of Wight. Earth and Environmental Science Transactions of the Royal Society of Edinburgh, Edinburgh.

Szadziewski, R., Gilka, W., and Sontag, E. 2007. First descriptions of males from Eocene Baltic amber in the fossil genus Mantohelea (Diptera: Ceratopogonidae). Alavesia, 1:37-40.

Wang, B., Rust, J., Engel, M.S., Szwedo, J., Dutta, S., Nel, A., Fan, Y., Meng, F., Shi, G., Jarzembowski, E.A., Wappler, T., Stebner, F., Fang, Y., Mao, L., Zheng, D., and Zhang, H. 2014. A diverse paleobiota in early Eocene Fushun amber from China. Current Biology, 24:1606-1610.

Wappler, T. 2003. Die Insekten aus dem Mittel-Eozän des Eckfelder Maares, Vulkaneifel. Mainzer Naturwissenschaftliches Archiv, Beiheft 27:1-234.

Wappler, T. and Andersen, N.M. 2004. Fossil water striders from the middle Eocene fossil sites of Eckfeld and Messel, Germany (Hemiptera, Gerromorpha). Paläontologische Zeitschrift, 78:41-52.

Wappler, T. and Engel, M.S. 2003. The middle Eocene bee faunas of Eckfeld and Messel, Germany (Hymenoptera: Apoidea). Journal of Paleontology, 77:908921.

Weitschat, W. and Wichard, W. 2010. Baltic Amber, p. 80-115. In Penney, D. (ed.), Biodiversity of Fossils in Amber from the Major World Deposits. Siri Scientific Press, Manchester.

Zachos, J.C., Dickens G.R., and Zeebe, R.E. 2008. An early Cenozoic perspective on greenhouse warming and carbon-cycle dynamics. Nature, 451:279-283. 